\title{
Symptomatic postprandial hypotension in high paraplegia. Case report
}

\author{
A Catz MD, ${ }^{1,2,3}$ L Mendelson MD, ${ }^{1,2}$ P Solzi, $\mathrm{MD}^{1,2}$ \\ ${ }^{1}$ Loewenstein Rehabilitation Hospital, Ra'anana; ${ }^{2}$ Sackler Faculty of Medicine, Tel-Aviv \\ University, Tel-Aviv; ${ }^{3}$ IDF Medical Corps, Israel.
}

Symptomatic postprandial decrease in blood pressure has been described in patients with various autonomic disorders, but not in patients with spinal injuries. Presented herein is a 31 year old female patient with traumatic complete paraplegia under the T3 level, in whom postprandial hypotension (PPH) was observed. The PPH was preceded by an increase in insulin level and was followed by an acceleration of heart rate. Oral caffeine prevented the hypotension and alleviated the symptoms. It is suggested that the PPH might be manifested as a result of damage to an upper thoracic spinal baroreflex. Clinical investigation of $\mathrm{PPH}$ is recommended for patients with high paraplegia.

Key words: PPH - postprandial hypotension; high paraplegia; spinal baroreflex; caffeine.

Postprandial hypotension (PPH) may occur in patients with impaired autonomic function; ${ }^{1}$ sometimes the decrease in blood pressure (BP) is symptomatic. ${ }^{2} \mathrm{PPH}$ was demonstrated in association with various conditions of autonomic dysfunction, including autonomic failure, ${ }^{3}$ diabetes mellitus,${ }^{4}$ tabes dorsalis, ${ }^{5}$ ganglionic blockage ${ }^{6}$ and old age. ${ }^{7}$

Although patients with complete cervical spinal cord lesion have severe sympathetic autonomic impairment, they did not show a reduction in $\mathrm{BP}$ after food ingestion in a previous study. ${ }^{8}$ To the best of our knowledge, this is the first report of a paraplegic patient with symptomatic $\mathrm{PPH}$.

\section{Case report}

A 31 year old female with traumatic paraplegia under the level of the third thoracic segment (T3) since 1976 was admitted to the Spinal Department of Loewenstein Rehabilitation Hospital. She suffered from dizziness, drowsiness, weakness and palpitations in the sitting position, immediately after meals. These symptoms sometimes prevented her from getting up from bed, and

Correspondence: Loewenstein Rehabilitation Hospital, 278 Achuza St, PO Box 3, Ra'anana 43100, Israel. she avoided eating when she planned activities that were not possible in the supine position. The patient in general ate little and was of slight build.

On physical examination, her general condition was good. Blood pressure was $95 / 60 \mathrm{mmHg}$ and pulse rate (PR) was $60 / \mathrm{min}$. Examination of lungs, heart and chest revealed no abnormalities. Neurological examination revealed complete spastic paraplegia below the T3 level. Routine laboratory tests (blood count, ESR, electrolytes, liver and kidney functions) were within normal limits.

To discover the cause of her complaint, $\mathrm{BP}, \mathrm{PR}$ and some biochemical and hormonal plasma constituents were measured before and after the ingestion of a meal. Results were compatible with a diagnosis of PPH. The hypotensive effect disappeared when the tests were repeated with the oral administration of $250 \mathrm{mg}$ caffeine before the meal.

\section{Materials and methods}

The tests were conducted after a $12 \mathrm{hr}$ fast. During testing the patient lay flat on a tilt bed, held with wide bands fixed around chest, hip girdle and knees. No pressure was applied to the abdomen. A cannula was inserted into a cubital vein and irrigated 
with heparin diluted to $50 \mathrm{u} / \mathrm{ml}$. A meal consisting of $60 \mathrm{~g}$ Isocal and $55 \mathrm{~g}$ Maxigul in $300 \mathrm{ml}$ of milk was administered (Table I). $\mathrm{BP}$ and PR were monitored at least twice every $10 \mathrm{~min}$ from $76 \mathrm{~min}$ before the meal to 105 min after the meal. The bed was tilted to $35 \mathrm{deg}$ for $10 \mathrm{~min}$ periods, at $25 \mathrm{~min}$ before the meal and at 45 and 95 min following the meal. Blood samples for glucose, insulin, plasma renin activity (PRA), sodium $(\mathrm{Na})$ and potassium $(\mathrm{K})$ testing were drawn through the cannula before and after the meal, in supine and tilted positions.

The procedure was repeated 24 hours later. Measurements were begun at $56 \mathrm{~min}$ before the meal; at $30 \mathrm{~min}$ before the meal $250 \mathrm{mg}$ caffeine was ingested. Blood sampling was omitted.

\section{Results}

\section{Basal haemodynamic and humoral} measurements

On the first day of testing, before the meal, and with the patient in the supine position, systolic blood pressure fluctuated between 90 and $101 \mathrm{mmHg}$ and diastolic between 50 and $64 \mathrm{mmHg}$; MBP was $66-80 \mathrm{mmHg}$. Pulse rate was $57-66 \mathrm{bpm}$ (Fig 1a, b). Plasma $\mathrm{Na}$ was $137 \mathrm{mEq} / 1$, K $4.3 \mathrm{mEq} / \mathrm{lit}$, glucose $63-67 \mathrm{mg} / 100 \mathrm{ml}$, PRA $1.0-1.1 \mathrm{ng} /$ $\mathrm{ml} / \mathrm{hr}$, and insulin 5.0-5.8 $\mu \mathrm{u} / \mathrm{ml}$ (Fig $1 \mathrm{c}$, d, e). Basal blood pressure and heart rate were lower than those of healthy subjects but similar to those of previously studied tetraplegic patients. ${ }^{9}$ The $\mathrm{Na}, \mathrm{K}$ and PRA were within normal limits, but the glucose and insulin levels were close to those reported after $24 \mathrm{hr}$ fasting in healthy subjects. ${ }^{10}$

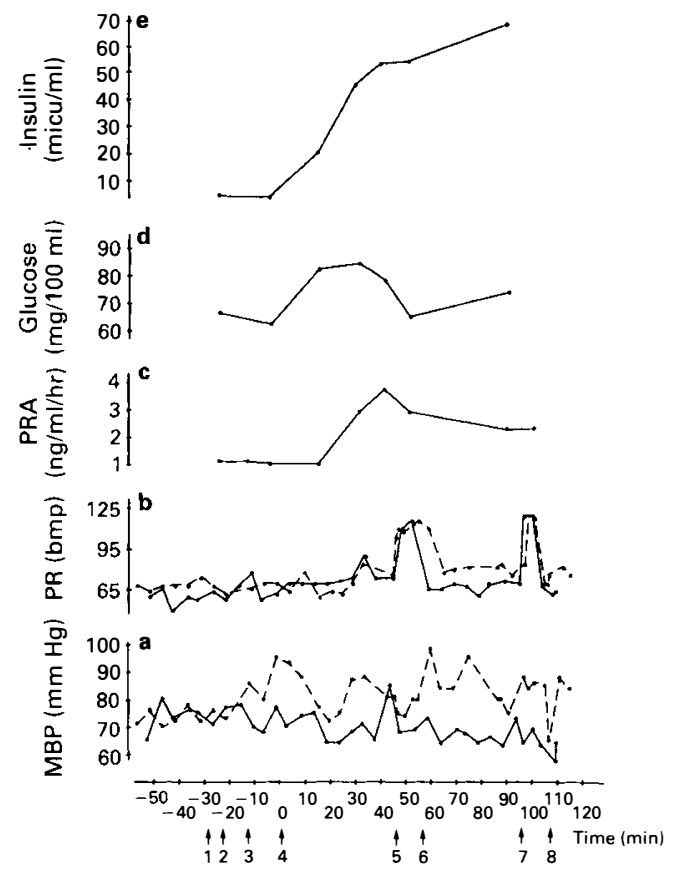

Figure 1 Haemodynamic and humoral variables before and after the meal, in supine and head-up tilt positions, without caffeine (continuous line) and with caffeine (segmented line). (a) Mean blood pressure (MBP). (b) Pulse rate (PR). (c) Plasma renin activity (PRA). (d) Plasma glucose level. (e) Plasma insulin level. Arrows 1: Caffeine ingestion $(250 \mathrm{mg}) ; 2,5,7: 35 \mathrm{deg}$ tilt; 3, 6, 8: Bed supine; 4: Meal.

\section{Haemodynamic and humoral effects of the meal}

The mean supine post prandial MBP $(68.8 \mathrm{mmHg}, \mathrm{SD}=6.0)$ was significantly lower than the mean basal MBP $(73.8 \mathrm{mmHg}, \mathrm{SD}=3.9)(p<0.01)$; this difference increased during the second hour

Table I Meal constituents

\begin{tabular}{lccccc}
\hline & $\begin{array}{c}\text { Carbohydrates } \\
(\mathrm{g})\end{array}$ & $\begin{array}{c}\text { Fats } \\
(\mathrm{g})\end{array}$ & $\begin{array}{c}\text { Proteins } \\
(\mathrm{g})\end{array}$ & $\begin{array}{c}\text { Na } \\
(\mathrm{g})\end{array}$ & $\begin{array}{c}\text { Energy } \\
(\mathrm{kcal})\end{array}$ \\
\hline 60 g Isocal & 35.8 & 11.8 & 12.0 & 0.14 & 282 \\
55 g Maxigul & 54.9 & - & - & 0.13 & 220 \\
300 ml milk & 15.0 & 3.0 & 9.0 & 0.15 & 123 \\
Total & 105.7 & 14.8 & 21.0 & 0.42 & 625 \\
\hline
\end{tabular}


after the meal (mean supine $\mathrm{MBP}=$ $66 \mathrm{mmHg}, \mathrm{SD}=3.9)$ and was even more significant $(p<0.0005)$ (Fig 1a). The mean $\mathrm{PR}$ following food ingestion $(70.1 \mathrm{bpm}$, $\mathrm{SD}=4.9$ ) was significantly higher than the mean basal PR $(62.3 \mathrm{bpm}, \quad \mathrm{SD}=2.9)$ $(p<0.0005)$ (Fig 1b). $\mathrm{Na}$ and $\mathrm{K}$ levels remained unchanged after the meal $(135-138 \mathrm{mEq} / \mathrm{l}$ and $4.2-4.6 \mathrm{mEq} / 1$, respectively). The glucose level reached a peak of $85 \mathrm{mg} / 100 \mathrm{ml}$ at $30 \mathrm{~min}$ after start of the meal, and then sloped down to $66-74 \mathrm{mg} / 100 \mathrm{ml}$ (Fig 1d). Insulin reached a level of $46 \mu \mathrm{u} / \mathrm{ml}$ (about 8 times the basal level) when the glucose level was $85 \mathrm{mg} / 100 \mathrm{ml}$, and then continued to rise to $68 \mu \mathrm{u} / \mathrm{ml}$ (about 13 times the basal level) despite the reduction in the glucose level (Fig 1e). These insulin levels were much higher than expected at the patient's glucose levels. ${ }^{11}$ PRA reached a peak value of $3.7 \mathrm{ng} / \mathrm{ml} / \mathrm{hr}$ at $40 \mathrm{~min}$ after start of the meal and then decreased to $2.4 \mathrm{ng} / \mathrm{ml} / \mathrm{hr}$ (Fig 1c).

\section{Haemodynamic clinical and humoral effects of meal plus tilt}

The tilt had little effect on BP, either before or after the meal (Fig 1A). On the other hand, tilting caused PR acceleration. The acceleration was slight prior to food ingestion (to 71-88 bpm), but very prominent after the meal (to 111-120 bpm) (Fig 1B). The patient was asymptomatic when tilted to 35 degrees during fasting, but she reported palpitations, dizziness, nausea and 'black spots' in the visual field when tilted after the meal. PRA was not elevated during tilt.

\section{Haemodynamic effects of meal plus caffeine}

Ingestion of caffeine alone elevated the basal MBP from $70-79 \mathrm{mmHg}$ to $95 \mathrm{mmHg}$. The mean supine MBP after the meal with caffeine $(83.6 \mathrm{mmHg}, \mathrm{SD}=8.3)$ remained higher than the mean basal MBP $(73.7 \mathrm{mmHg}, \mathrm{SD}=3.6)$. Even during tilt, the mean postprandial MBP $(81.5 \mathrm{mmHg}$, $\mathrm{SD}=5.7)$ was higher than the mean basal MBP (Fig 1a).

Caffeine ingestion did not prevent the postprandial tachycardia and palpitations
(Fig 1b). It was quite clear from the patient's report, however, that significant symptomatic relief was achieved with caffeine ingestion.

\section{Discussion}

The study showed that in our present patient food was a factor inducing symptomatic hypotension. Her BP was significantly reduced after food intake, and symptoms that did not appear before the meal in either supine or tilt position appeared after the meal in tilt position. Ingestion of caffeine $(250 \mathrm{mg})$ which prevented PPH in patients with autonomic failure ${ }^{12}$ also prevented the reduction in BP in our patient. The $\mathrm{PPH}$ followed an accessive increase in insulin level (Fig 1a, e). The reason for such an increase is not clear, but it is plausible that $\mathrm{PPH}$ was initiated by insulin-induced vasodilatation. ${ }^{13}$

Postprandial vasodilatation followed by increased intestinal blood flow is a physiological phenomenon. ${ }^{14} \mathrm{PPH}$, however, is unusual in both healthy subjects and patients with complete tetraplegia. ${ }^{7,8}$ In healthy subjects, the postprandial vasodilatation is probably buffered by vasoconstriction, induced mainly by the sympathetic baroreflexes, which allows physiological redistribution of the blood flow to the splanchnic $^{15}$ and hepatic ${ }^{16}$ beds and prevents a decrease in BP. ${ }^{5}$ In patients with complete tetraplegia $\mathrm{PPH}$ does not occur, probably because the vasoconstrictor buffering is not prevented by de-efferentation of the reflexes originating in the baroreceptors of the aortic arc and carotid sinus. ${ }^{8}$ This could be explained by some of the mechanisms suggested as preventing orthostatic hypotension in chronic tetraplegics. ${ }^{17}$

One possible explanation for the symptomatic PPH in our patient and not in tetraplegics, is an upper thoracic spinal baroreflex that had been interrupted whilst preserving the upper sympathetic nerve supply to the cerebral vessels and a part of the heart. Such a purely spinal upper thoracic BP reflex was suggested by Gilliatt et al. ${ }^{18}$ This hypothesis was supported by Brown and Malliani who showed a spinal reflex ho- 
meostatic regulation of $\mathrm{BP}$ in cats, with increased sympathetic discharge through the white ramus at the third thoracic level. ${ }^{19}$

Preservation of the ability to activate cardiac nerves through cervical and uppermost thoracic spinal segments apparently allowed in this particular patient prominent reactive tachycardia, which is limited in complete tetraplegics. ${ }^{5}$ Preservation of her sympathetic supply to cerebral vessels, could impair autoregulation of cerebral blood flow (CBF) at low $\mathrm{BP}$, which is possible in patients with chronic tetraplegia. ${ }^{20}$ Therefore, symptoms such as palpitations, dizziness and drowsiness were likely to appear in this patient in contrast to patients with complete cervical lesions. These suggestions, however, should be further evaluated in a group of patients with high paraplegia.

Although the compensatory mechanism for postprandial vasodilatation was damaged, the compensatory reaction to head-up tilt remained intact: PPH was demonstrated in the absence of orthostatic hypotension. Different responses to tilt and food administration were also expressed in the level of PRA. Renin release, which is probably dependent on the decrease in renal perfusion pressure, ${ }^{21}$ remained unchanged in spite of the pre meal head-up tilting, but was enhanced in the supine position after the meal (Fig 1c). It seems, therefore, that the mechanism buffering the tilt effect may be different from that buffering the food effect. Caffeine intake caused an elevation in BP before and after the meal, so that BP was above the basal level most of the time. On the other hand, the effect of caffeine on PR was diverse and insignificant (Fig 1a, b). These results were probably caused by the combination of the direct cardio-acceleratory effect and the secondary vagally-mediated bradycardia effect of caffeine. ${ }^{12}$ The effect of caffeine on BP but not on PR may explain the relief of symptoms compatible with brain ischemia such as dizziness, nausea and visual disturbances, without relief of the palpitations, which followed tachycardia.

The findings in this study suggest that an upper thoracic spinal lesion may cause symptomatic PPH. Since caffeine may alleviate symptoms of $\mathrm{PPH}$, clinical examination for the presence of PPH might be beneficial to these patients.

\section{References}

1 Bannister R, Christensen NJ, da Costa DF, Mathias CJ, Wright H, Ukachii-lois J (1984) Mechanisms of post-prandial hypotension in autonomic failure. J Physiol 349: 67P.

2 Seyer-Hansen K (1977) Post prandial hypotension. Br Med J 2: 1262.

3 da Costa DF, McIntosh C, Bannister R, Christensen NJ, Mathias CJ (1985) Unmasking of the cardiovascular effects of carbohydrates in subjects with sympathetic denervation. J Hypertens 3(Suppl 3): 447-448.

4 Page MN, Watkins PJ (1976) Provocation of postural hypotension by insulin in diabetic autonomic neuropathy. Diabetes 25: 90-95.

5 Mathias C, Da Costa D, Bannister R (1988) Postcibal hypotension in autonomic disorders. In: Bannister R, editor. Autonomic Failure. A Textbook of Clinical Disorders of the Autonomic Nervous System. Oxford University Press, Oxford: 367-380.

6 di Salvo RJ, Bloom WL, Brust AA, Ferguson RW, Ferris EB (1956) A comparison of metabolic and circulatory effects of epinephrine, norepinephrine and insulin hypoglycaemia with observations on the influence of autonomic blocking agents. J Clin Invest 35: 568-577.

7 Lipschitz LA, Nyquist RH, Wei JY, Rowe JW (1983) Postprandial reduction in blood pressure in the elderly. New Engl J Med 309: 81-83.

8 Mathias CJ, Frankel HL (1986) The neurological and hormonal control of blood vessels and heart in spinal man. J Auton Nerv Syst (Suppl): 457-464.

9 Frankel HL, Michaelis LS, Golding DR, Beral V (1972) The blood pressure in paraplegia. Paraplegia 10: 193-198.

10 Braunwald E, Isselbacher KJ, Petersdorf RG, Wilson DJ, Martin JB, Fauci AS, editors (1987) Harrison's Principles of Internal Medicine. McGraw-Hill, New York: 1753-1807.

11 Guyton AC (1986) Textbook of Medical Physiology. WB Saunders, Tokyo: 923-936.

12 Onrot J, Goldberg MR, Biaggioni I, Hollister AS, Kincaid D, Robertson D (1985) Haemodynamic and humoral effects of caffeine in autonomic failure. Therapeutic implications for postprandial hypotension. New Engl J Med 313: 549-554.

13 Brown RT, Polinsky RJ, Lee JK, Deeter JA (1986) Insulin-induced hypotension and neurogenic orthostatic hypotension. Neurology 36: 1402-1406. 
14 Qamar MI, Read AE (1986) The effect of feeding and sham feeding on superior mesenteric blood flow in man. J Physiol 377: 59P.

15 Norryd C, Dencker H, Lunderquist A, Olin T, Tylen U (1975) Superior mesenteric blood flow during digestion in man. Acta Chir Scand 141: 197-202.

16 Svensson CK, Edwards JD, Mauriello PM, Barde SH, Foster AC, Lanc RA et al (1983) Effect of food on hepatic blood flow: implications in the 'food effect' phenomenon. Clin Pharmacol Ther 34: 316-323.

17 Figoni SF (1984) Cardiovascular and hemodynamic responses to tilting and to standing in tetraplegic patients: a review. Paraplegia 22: 99-109.

18 Gilliatt RW, Guttmann L, Whitteridge D (1948) Inspiratory vaso-constriction in patients after spinal injuries. J Physiol 107: 67-75.

19 Brown AM, Malliani A (1971) Spinal sympathetic reflexes initiated by coronary receptors. J Physiol 212: 685-705.

20 Cole JD (1988) The pathophysiology of the autonomic nervous system in spinal cord injury. In: Illis LS, editor. Spinal Cord Dysfunction: Assessment. Oxford University Press, Oxford: 201-235.

21 Mathias CJ (1988) Cardiovascular control in spinal man. Ann Rev Physiol 50: 577-592. 